\title{
Insulin-anti-insulin complexes in diabetic women and their neonates
}

\author{
U. Di Mario, F. Fallucca, P. Gargiulo, C.Tiberti, A. Scardellato, P. Arduini, A. Pachi' and D. Andreani \\ Cattedra di Endocrinologia I, University of Rome "La Sapienza", Rome, Italy
}

Summary. It is known that insulin does not cross the placenta, whereas maternal anti-insulin antibodies do. We have therefore investigated insulin antibodies and insulin-anti-insulin complexes both in pregnant diabetic women during pregnancy and in umbilical cord blood from their new-born infants. Forty-seven diabetic pregnant women and 23 new-born infants of these diabetic women were studied. All the pregnant patients were studied at the end of pregnancy and, in 27 , at least on one other occasion during pregnancy. All the patients were treated with insulin during pregnancy: 26 had Type 1 (insulin-dependent) diabetes, 14 Type 2 (non-insulin-dependent) diabetes and seven had gestational diabetes. Insulin antibodies were found in $62 \%$ of the Type 1 diabetic patients, in $71 \%$ of the Type 2 diabetic patients and in $43 \%$ of the gesta- tional diabetic patients. They were present in $48 \%$ of the infants studied. Insulin-anti-insulin complexes were found in $37 \%$ of the women with Type 1 diabetes, in $21 \%$ of those with Type 2 diabetes and in $14 \%$ of those with gestational diabetes. Complexes were found in $38 \%$ of the new-born infants. The presence of these complexes in the babies was more strongly correlated with their occurrence in their mothers at the beginning than at the end of pregnancy. Insulin-anti-insulin complexes are thus present in the neonatal circulation. They may differ from those in their mothers and they may have pathophysiological and clinical importance.

Key words: Insulin antibodies, insulin-anti-insulin complexes, diabetic pregnancy.
Diabetic pregnancy is useful for the study of several immune phenomena. The immune system in normal pregnancy is thought to be in a state of 'activation' rather than in a state of 'depression' [1]. In diabetes, several immunological abnormalities may be present and these may be related to pathogenic events, metabolic derangement and insulin therapy [2].

In diabetic pregnancy, several immune phenomena may be present temporarily as a consequence of both diabetes and pregnancy. Moreover, some abnormal immune factors can cross the placenta and interfere with fetal metabolism and development. In particular, maternal antibodies to exogenous insulin may be transferred to the fetal circulation, whereas maternal insulin does not cross the placenta. The significance of insulin antibodies in fetal blood during the first months of fetal development and their possible pathophysiological effects and interactions with fetal insulin are unclear and these antibodies have not received the attention they merit.

In this study, we looked for the possible presence of insulin-anti-insulin complexes in cord blood and examined the relationships between these complexes in new-born infants with maternal insulin antibodies and insulin-anti-insulin complexes.

\section{Subjects and methods}

\section{Subjects}

A total of 47 pregnant diabetic patients, all attending the same clinic, were studied. Twenty-three were investigated with their babies. All the pregnant patients were tested at the end of pregnancy; 27 were also tested in the first trimester of pregnancy. Twenty-six had Type 1 diabetes, 14 Type 2 diabetes and seven gestational diabetes. All patients were treated with insulin, either monocomponent or semi-synthetic human, except in two cases. Infant cord blood was also studied.

\section{Methods}

Insulin antibodies, estimated as insulin binding capacity, were evaluated by the method of Ortved Andersen et al. [3] as modified by Mustaffa et al. [4] with a few further minor modifications [5]. Values above $10 \mathrm{mU} / 1$ were considered indicative of the presence of antibodies.

Insulin-anti-insulin complexes were measured by a modification of the techniques described by Jayarao et al. [6] and Virella et al. [7]. Serum to be tested was split into two aliquots. One aliquot was dialysed overnight in buffer glycine- $\mathrm{HCl}(\mathrm{pH} 3)$, added to dextran-charcoal in glycine- $\mathrm{HCl}$, incubated for $30 \mathrm{~min}$ at room temperature, centrifuged and finally the supernatant was dialyzed against barbital buffer, $\mathrm{pH}$ 7.4. To this mixture and the other aliquot, adequately diluted, radiolabelled insulin was added. After $2 \mathrm{~h}$ incubation at $37^{\circ} \mathrm{C}$, the addition of dextran-charcoal and centrifugation, the supernatants and precipitates were counted. 
The insulin-anti-insulin complexes were calculated as the difference between 'total' antibody and 'free' antibody. 'Total' and 'free' antibodies were calculated as follows: $100-(\mathrm{cpm}$ in the precipitate $\mathrm{cpm}$ in the supernatant/total $\mathrm{cpm}) \times 100$ - background. Positive values of 'total' insulin antibodies were taken as $>$ mean +2 SD of normal values and are expressed as a percentage (i. e. $>10 \%$ ). Positive values of insulin - anti-insulin complexes were $>$ mean +2 SD of values found in normal subjects (i.e.> 7\%). The sensitivity of this technique in assaying the sole presence of insulin antibodies was slightly different from Andersen's method [3] (Table 1).

Fisher's exact test was used for statistical evaluation.

\section{Results}

\section{Insulin antibodies}

Diabetic mothers: Insulin antibodies were found at the end of pregnancy in $62 \%$ of the Type 1 diabetic patients (median $15.5 \mathrm{mU} / 1$, interquartial range $<10-45 \mathrm{mU} / \mathrm{l}$ ), in $71 \%$ of the Type 2 diabetic patients (median $26.5 \mathrm{mU} / 1$; interquartial range $<10-79 \mathrm{mU} / \mathrm{l}$ ) and in $43 \%$ of the gestational diabetic patients (median $<$ $10 \mathrm{mU} / 1$, interquartial range $<10-13 \mathrm{mU} / 1$ ). No significant difference was found when the levels of insulin antibodies in the Type 1 diabetic patients at the beginning of pregnancy (median $18 \mathrm{mU} / 1$, interquartial range $<10-43 \mathrm{mU} / \mathrm{l}$ ) were compared with those at the end of pregnancy.

Neonates: Insulin antibodies were found in $48 \%$ of the neonates studied. Their levels were similar in the neonates (median $<10 \mathrm{mU} / 1$, interquartial range $<$ $10-28 \mathrm{mU} / \mathrm{l})$ and in the mothers at the end of pregnancy (media $13 \mathrm{mU} / 1$, interquartial range $<10-30 \mathrm{mU} / 1$; Table 1).

\section{Insulin-anti-insulin complexes}

Mothers: Quantifiable insulin-anti-insulin complexes were found in $37 \%$ of the Type 1 diabetic patients at the beginning of pregnancy (median $<7 \%$, interquartial range $<7-13.3 \%$ ) and in $27 \%$ of the Type 1 diabetic patients at the end of pregnancy (median $<7 \%$, interquartial range $<7-7.1 \%$ ). Complexes were also present in $21 \%$ of the Type 2 diabetic mothers at the end of pregnancy (three patients: $8 \%, 9 \%, 82 \%$ ) and in $14 \%$ of gestational diabetic patients (one patient: $8 \%$ ).

Neonates: Insulin-anti-insulin complexes were present in the infants of diabetic mothers $(38 \%$ of infants of Type 1 and $43 \%$ of Type 2 diabetic mothers; Table 1). There was a significant correlation between the presence of the complexes in neonates and their occurrence in their mothers, and this correlation was much stronger when the data in neonates were correlated with data from the mothers in the first trimester of pregnancy $(p<0.0005)$ than at the end of pregnancy $(p<0.01)$.

\section{Discussion}

This study shows that insulin-anti-insulin complexes are present in the circulation of some infants of Type 1 diabetic mothers. The amount of complexed anti-insulin antibody is related not only to the total amount of the antibody, but is also related to the affinity and avidity of the maternal insulin antibody.

There was a strong correlation between the presence of complexes in cord blood and in the maternal circulation. However, their presence in the fetus does not merely represent passive transfer of insulin antibodies across the placenta. The levels of the complexes in the neonate do not reflect those of the mother at the end of pregnancy, but the average complex levels throughout pregnancy.

Insulin antibodies can easily cross the placenta, whereas insulin is not transferred in significant amounts. In the fetus, these antibodies react with a different antigen, fetal endogenous insulin, rather than exogenous heterologous insulin as in the mother. The antigen/antibody molar ratio is substantially different. In the mother, the antibody reacts with massive doses of insulin, of either high or low immunogenicity, administered in subcutaneous boluses, often twice a day, while in the fetus, it reacts with continuously produced pancreatic insulin. The amount of insulin produced by the fetal pancreas varies greatly between the first months of gestation until term, whereas the amount of insulin antibodies crossing the placenta does not usually vary significantly during pregnancy. From a situation probably characterized by antibody excess at the beginning of pregnancy, the proportion between antigen and antibody becomes more balanced, as the fetal pancreas produces increasing amounts of insulin.

It is likely that both the fate and the significance of the fetal insulin-anti-insulin complexes are different from those of the mother.

Clearance of fetal complexes seems slower than that in the mother. It is not known whether insulin antibodies in fetal circulation may be easily retransferred to the maternal circulation, but it is unlikely that the complexes are freely exchanged.

Whereas, in the mother, small to medium size complexes are rapidly removed by the kidney and the reticulo-endothelial system [8], in the fetus, clearance is not as efficient, particularly in the infants of diabetic mothers in whom the duration of gestation is often shortened. This could explain why, in those few cases in which the insulin antibody levels are high in the mother at the beginning of pregnancy and low at the end, the insulin-anti-insulin complex levels in the fetus are comparable to those found in the mother in the first months of pregnancy.

Our group and others have suggested a correlation between the presence of insulin antibodies and the occurrence of neonatal complications [9-13]. On the other hand, the possible damage induced by the deposition 


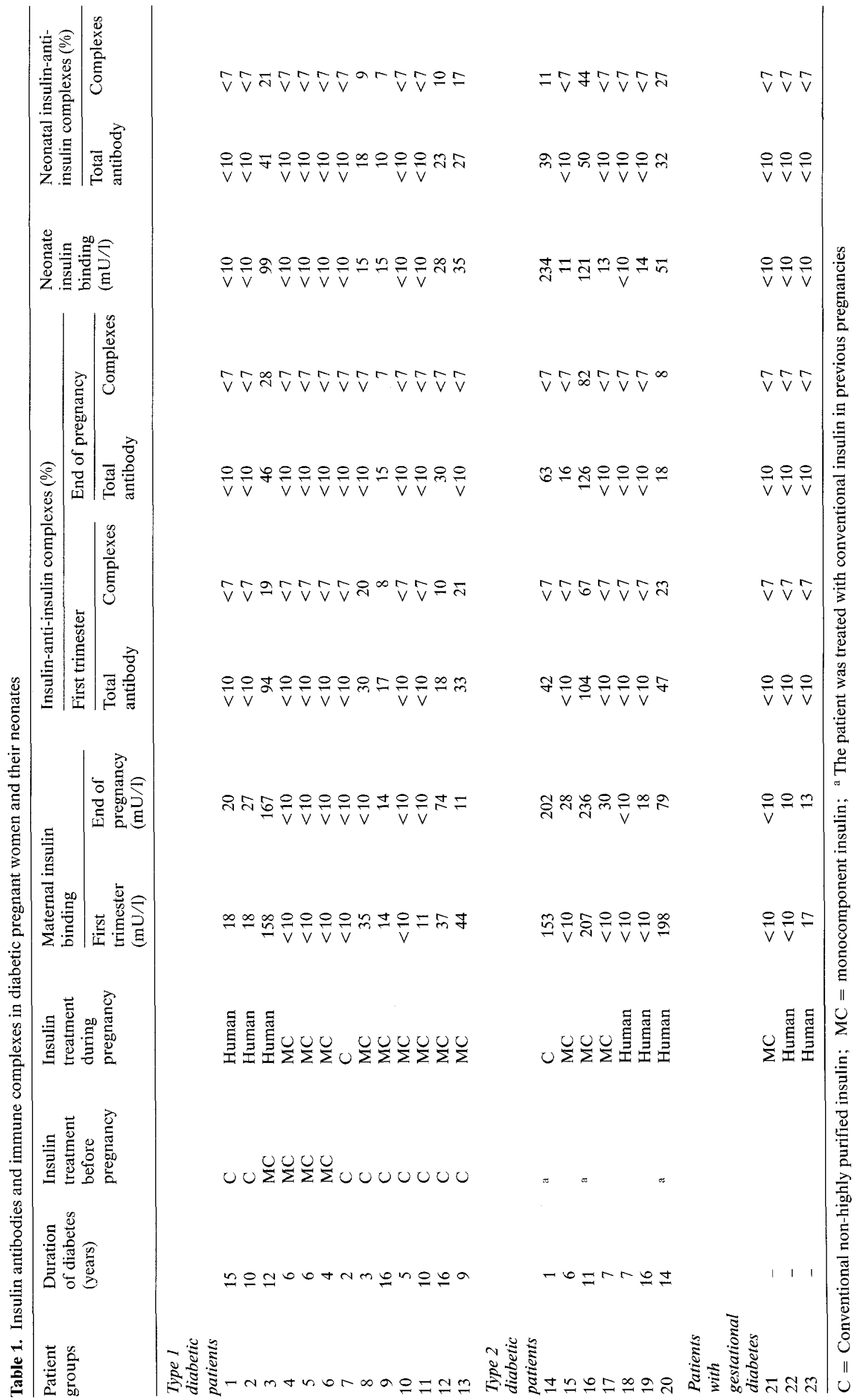


and presence of immune complexes is well known, both in diabetic patients $[6,14]$ and in pregnant women with clinical complications [15, 16]. Moreover, it is well known that the injection of insulin antibodies may induce a diabetic-like syndrome in normal animals [17]. The presence of insulin-anti-insulin complexes may theoretically interfere with the placental circulation and explain some of the neonatal complications of diabetic pregnancy, in particular macrosomia and neonatal hypoglycaemia with neutralising or abrupt release of substantial amounts of neonatal insulin.

\section{References}

1. Gleicher N, Siegel I (1983) Immunology of pregnancy. Wien Klin Wochenschr 95: 377-382

2. Andreani D, Di Mario U, Federlin K, Heding LG (eds) (1984) Immunology in diabetes. Kimpton, London

3. Ortved Andersen O, Brunfeldt K, Albidgard F (1972) A method for quantitative determination of insulin antibodies in human plasma. Acta Endocrinol 69: 195-208

4. Mustaffa BE, Dagget PR, Nabarro JDN (1977) Insulin binding capacity in patients changed from conventional to highly purified insulins. An indicator of likely response. Diabetologia 13: 311-315

5. Irvine WJ, Di Mario U, Feek CM, Ting A, Morris PJ, Gray RS, Duncan LJP (1978) Insulin antibodies in relation to islet cell antibodies and HLA antigens in insulin-dependent (Type 1) diabetes. J Clin Lab Immunol 1: 111-114

6. Jayarao K, Page Faulk W, Karam JH, Grodsky GM, Forsham PH (1974) Evidence in support of the concept of immune complex disease in insulin treated diabetics. In: Bastenie PA, Gepts W (eds) Immunity and autoimmunity in diabetes mellitus. Excerpta Medica, Amsterdam, pp 225-263
7. Virella G, Russel D, Laimins M, Colwell J (1980) Simplified method for detecting anti-insulin antibodies and insulin-antiinsulin immune complexes. Clin Chem 26: 1357-1359

8. Mannik M, Haakenstad AO, Arend WP (1974) The fate and detection of circulating immune complexes. Prog Immunol 2: 91-101

9. Martin FIR, Dahlenburg GW, Russel J, Jeffrey P (1975) Neonatal hypoglycaemia in infants of insulin-dependent diabetic mothers. Arch Dis Child 50: 472-476

10. Heding LG, Persson B, Strangenberg M (1980) B-cell function in newborn infants of diabetic mothers. Diabetologia 19:427-432

11. Fallucca F, Iavicoli M, Russo A, Melillis, Ventriglia L, De Gado F, Pachì A, Andreani D (1980) IgG insulin antibodies in the foetus of diabetic mother. In: Pinchera A, Doniach D, Fenzi GF, Baschieri L (eds) Autoimmune aspects of endocrine disorders. Academic Press, New York, pp 311-312

12. Mylvaganam R, Stowers JM, Steel JM, Wallace J, MacHendry JC, Wright AD (1983) Insulin immunogenicity in pregnancy: maternal and fetal studies. Diabetologia 24: 19-25

13. Di Mario U, Andreani D, Iavicoli M, Gargiulo P, Galfo C, Musacchio N, Fallucca $F(1982)$ Humoral immunity in pregnant diabetic patients: islet cell antibodies, insulin antibodies and immune complexes. Diabetologia 23: 164 (Abstract)

14. Di Mario U, Iavicoli M, Andreani D (1980) Circulating immune complexes in diabetes. Diabetologia 19: 89-92

15. Theophilopoulos AN, Gleicher N, Pereira AB, Dixon FJ (1981) The biology of immune complexes and their possible role in pregnancy. Am J Reprod Immunol 1: 92-105

16. Vazquez-Escobosa C, Perez-Medina R, Gomez-Estrada H (1983) Circulating immune complexes in hypertensive disease of pregnancy. Obstet Gynecol 62: 45-48

17. Wright PH (1961) The production of experimental diabetes by insulin antibodies. Am J Med 31: 892-900

Dr. U. Di Mario

Clinica Medica 2 (Endocrinologia 1)

Policlinico Umberto 1

I-00161 Rome

Italy 